\title{
Study on Seepage-Induced Debris Flows Initiation under the Rainfall Action for Loose Soil
}

\author{
Chi $\mathrm{LI}^{1}$, Wenhui ZHU ${ }^{1}$ and Xiaobing $\mathrm{LU}^{2}$ \\ ${ }^{1}$ College of Civil Engineering, Inner Mongolia University of Technology, 49 Aimin Road, Huhhot, \\ 010051, Inner Mongolia, China; tjdxlch2003@126.com \\ ${ }^{2}$ Institute of Mechanics, Chinese Academy of Science, 15 Beisihuan West Road, Beijing, 100084, \\ China; xblu@sina.com
}

\begin{abstract}
Test soils were collected from debris flow source area in the Weijia groove, Beichuan county, Sichuan province. Indoor artificial rainfall model tank test has been designed; it can be used to simulate the process of debris flow initiation for slope loose soil under the rainfall action. The debris flow starting condition and confluence process have been measured in this test, through the analyzing the relationship of the rainfall intensity, duration time before the starting, and the total rainfall capacity at the starting moment, the relationship between the volume of production flow and the water to soil ratio in production flow. All these research results can be used to simulate debris flow initiation mechanism obtained from model test focused on the seepage-induced action and its influence factors.
\end{abstract}

\section{INTRODUCTION}

When it mentions to the research of debris flow, one of the main concerns is how debris flows are initiated. It is the basis of disaster prevention and reduction. Previous research has proven that the earthquake zone usually is the zone of most frequent debris flow activity in the world (USGS, 2011).

Iverson, et al. (1989), applying the growth and dissipation of pore water pressure in soil mechanics theory, studied the mechanisms of growth, dissipation, and maintenance of pore water pressure during the initiation and movement of debris flows (Iverson, R. M., 1997a; Iverson, R. M., 1997b; Iverson, R. M. et. al., 1989). Most previous research works focused on the mechanisms of rainfall induced slope failures (Sladen, J. A., et. al., 1985; Fleming, R. W., et. al., 1989; Sasitharan, S., et. al., 1994; Anderson, S. A., et. al., 1995; Zhu, J. H., et. al., 1998). The transformation to flows from rainfall-induced slides was commonly simulated by tests on anisotropically consolidated-undrained and constant-shear drained saturated specimens. Their test results showed that most failures involved some relatively slow initial deformation, followed by a rapid transformation of the soil mass into a viscous liquid. The development of a debris flow was separated into two different mechanisms, the initial 
drained slope failure followed by undrained mobilization of the flow.

Applying the unsaturated soil shear strength theory, the causes of rainfall-induced debris flow and its formation process has been studied. Brand (1981) postulated that the decrease of suction in the soil causes a reduction in effective normal stress on the potential failure surface, which in turn lowers the shear strength. The rainfall action mechanism and mechanical property change characteristics have been revealed for loose detrital material. The influence factors of the matrix attraction of unsaturated soil slope, such as intensity of rainfall, duration of rainfall, and saturated permeability coefficient of soil have been analyzed through numerical simulation. Above research showed the main factor contributing to rainfall-type debris flow initiation is the significant loss of attraction from the soil matrix due to rainfall infiltration (Chen, H., et. al., 2004; Take, W. A., et. al., 2003).

This paper focuses on the Wenchuan earthquake of May 12, 2008, which took place in the Beichuan County, Sichuan province. Weijia groove, which located in the Beichuan County, have steep terrain landform plus loose material accumulated on the slope after the earthquake, it can be provides the beneficial terrain conditions and abundant material source for debris flow initiation. After the earthquake, rain storms or strong rain have taken place in the Beichuan County in the next two months, these have contributed a plentiful water source to the initiation of debris flows, it became a main side effect or secondary disaster following the earthquake. As the research object, the landslide translating into debris flow under rainfall in the Beichuan County has been studied by author through numerical simulation (Li, C., et. al., 2010; Cui, P., 1992; Cui, P., 1993). The effects of the slope ratio, rainfall strength and soil moisture conditions have been analyzed. The initiation expansion of the plastic zone and the development of the tensile stress zone in the slope under rainfall have been investigated. It indicated that the zone with the high pore water pressure mainly near the slope toe with one fifth of the slope height. The pore water pressure at the slope toe was the highest, and decreased from the toe to top. The large horizontal displacements of the slope were mainly near the slope toe with one fifth of the slope height, and debris flow initiation under rainfall first began at the slope toe. Therefore, with the increase of the slope angle and rain strength and saturation degree, the stability of the slope decreased gradually to trigger the debris flow initiation. But the process of debris flow initiation for slope soil, especially, for loose soil with certain content of fine particle, need to be simulate under the rainfall action, with the purpose of understanding the humidifying process from unsaturated soil to saturated soil. In this study, we will focus the process of debris flow initiation for slope soil under the rainfall action, the indoor artificial rainfall model tank test will be designed; it can be used to simulate the process of debris flow initiation for loose soil under the rainfall action. All these research results can be used to present debris flow initiation mechanism originated from the seepage-induced action and its influence factors.

\section{EXPERIMENT}

The soil used in this study is collected from the loose soil in the Weijia groove debris flow source area. A grain-size analysis test was done on the retrieved soil. In this process, some particles with a grain size greater than $5 \mathrm{~mm}$ are taken away, the 
content of viscous grain and the content of fine particles with a grain size of less than $0.1 \mathrm{~mm}$ are the same, the particle grading distribute curve is shown in Fig.1. So, the test soil can be representative debris flow source area of original fine particle properties, and then, the debris flow initiation mechanism and its influence factors can be simulated through indoor experiments.

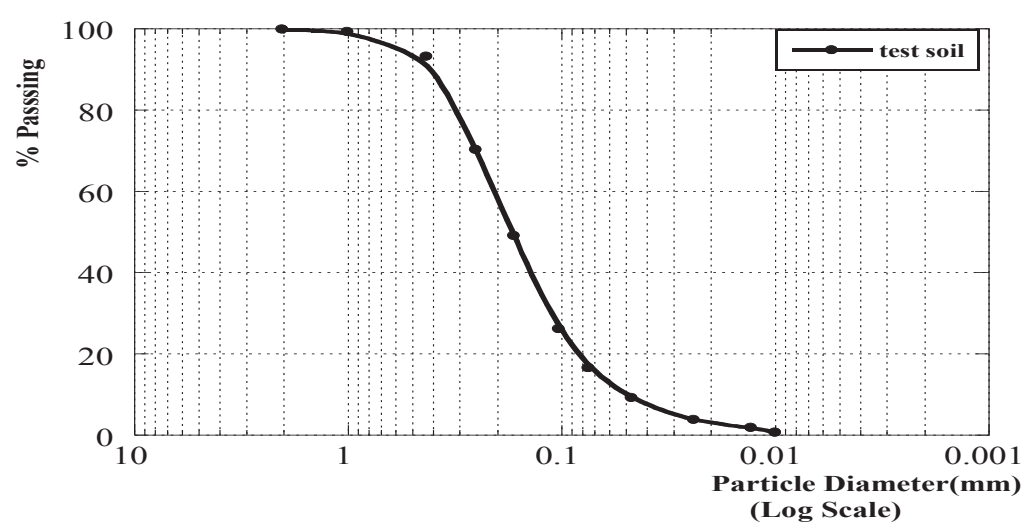

FIG. 1. Grain size distribution curves of test soil.

\section{Experimental Equipment}

A model tank device is made in Institute of Mechanics, Chinese Academy of Science, is shown in Fig.2. This model tank is developed by two slopes which composite to a certain intersect angle and inclination angle. The single slope is made by aluminum; the rectangle size is $100 \mathrm{~cm} \times 120 \mathrm{~cm}$. Before the test, a layer of glue is brushed on the slope surface, and then put the fine sand on it, after the glue solidified thoroughly, extra fine sand are cleaned from the slope surface, so as to make the rough slope surface simulating the real slope surface. According to the field survey from Weijia groove, the intersect angle sets up to $121^{\circ}$ and the inclination angle fits $27^{\circ}$ between the two slopes in the test. During the test, test soil is spread on the slope surface evenly, the thickness of soil is $10 \mathrm{~cm}$ and the volume is $0.12 \mathrm{~m}^{3}$ in each slope surface. A rainfall maker device is made by oneself, it equipped with three rows of sprayer, four sprayers on each row, and the total is twelve. A plastic bottle which area is $59.45 \mathrm{~cm}^{2}$ connected with the measuring cylinder, it can be used to measure the rainfall intensity after complete the artificial rainfall test. Moreover, a plastic basin is put near the intersect place of the two slope, it can be used to collect the production flow during the test. 


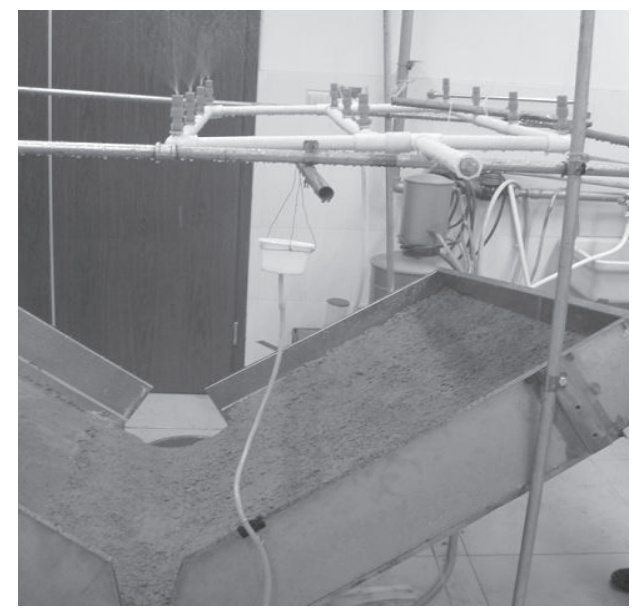

\section{FIG. 2. Model tank device.}

\section{Experimental Method and Procedure}

$\mathrm{Be}$ as the experimental variables, the rainfall intensity, the unit weight of cumulative production flow and the water to soil mass ratio can be measured in the test, the relationship between these experimental variables is analyzed after the test.

Firstly, the soil masses which the dry unit weight is $1005 \mathrm{~kg} / \mathrm{m}^{3}$ and water masses which the original water content maintains $8.4 \%$ are weighted, respectively. Next, some dry soil masses and water masses are mixed together until the mixture is uniform, and the mixture is placed into the model tank in five layers for compaction, compacted and galled with each layer, and the same is done for a total of five layers. Furthermore, we prepare the artificial rainfall test using three different kinds of rainfall, the starting time and the finish time, the soil deformation and landslide are observed in each test. After each test, the rainfall intensity which means the rainfall within unit time are measured, the unit weight of cumulative production flow are tested, and the water to soil mass ratio can be calculated after drying in oven.

\section{EXPERIMENTAL RESULTS AND DISCUSSION}

\section{Test Observations}

Some interesting phenomena are found in this artificial rainfall test. During the rainfall, the soils begin to slide from the slope toe firstly, the length of slider is about 1/5 or so of the slope width along the slope width direction, we can see it in Fig.3 (a). After that, block of soil around the slope toe goes to slide, and corrode gradually in the form of convex arc shape upward, shown in Fig.3 (b). Especially, fluidal water can't form on the slope surface when the rainfall intensity is small. The soils slide integrity with piece by piece. The fluidal water accumulate on the slope surface when the 
rainfall intensity is greater, the soil sliding more easily, and the top soil with liquefied or softening condition slide firstly.

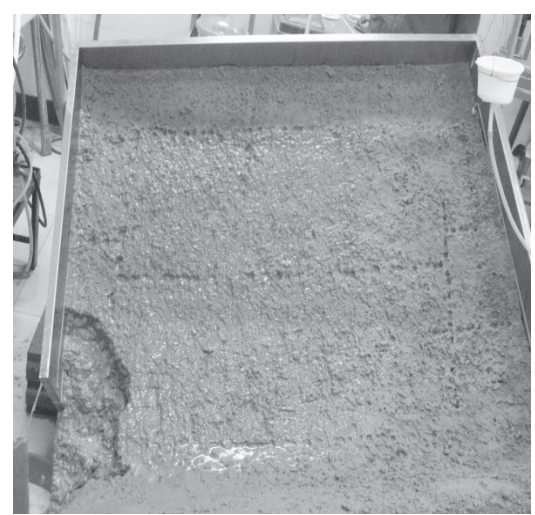

(a) beginning to slide

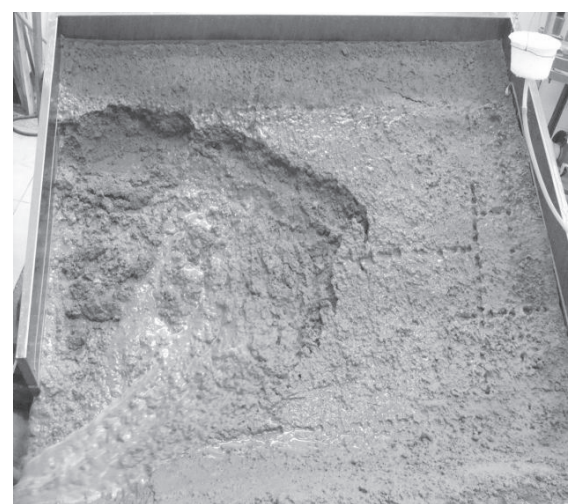

(b) during sliding

FIG.3. Test observations during the soil sliding.

\section{Relationship between Experimental Variables}

The relationship between slide starting time and the total rainfall is analyzed according to the three kind of different rainfall intensity, shown in Fig.4.

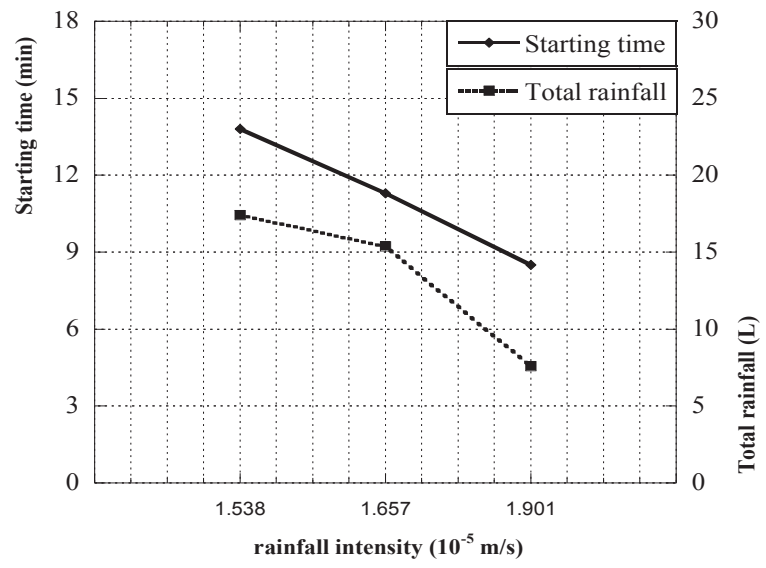

FIG.4. Relationship between starting time, the total rainfall and rainfall intensity.

From the Fig.4, we can see the starting time for the stable soil to slide shorten with the rainfall intensity increase, and the total rainfall also decrease. It shows that the scouring action from raindrop has a bad effect on the slope stability. This kind of 
scouring action act the component force on the slope soil along inclined slope surface, and the component force increases with the increasing of rainfall intensity, the slope loose soil trend to slide with strong rainfall intensity, but the total rainfall is not large.

The relationship between rainfall intensity, cumulative production flow and water to soil mass ratio of cumulative production flow is analyzed, shown in Fig.5, Fig.6 and Fig.7, respectively. From these figures, we can see cumulative production flow increase with the increasing of rainfall intensity during the same rainfall duration, that is, the speed of production flow is faster with the greater rainfall intensity. But the water to soil mass ratio of cumulative production flow decrease with the rainfall duration developed. This shows that the slope soil needs more water source to trigger to product flow at the beginning of rainfall, however, at the end of rainfall, a small amount of water can stimulate the soil production flow. During the whole rainfall process, the soil cumulative production flow unit weight increase first, then decrease, the maximum cumulative production flow unit weight decrease gradually with the increasing of rainfall intensity.

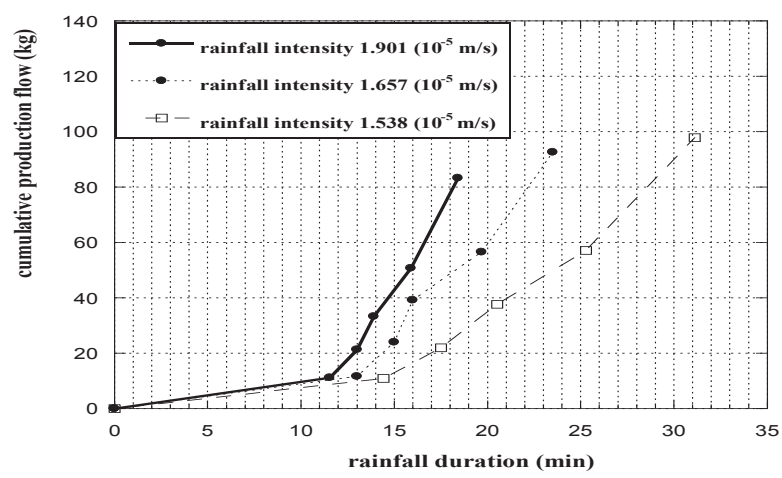

FIG. 5. Relationship between rainfall intensity and cumulative production flow.

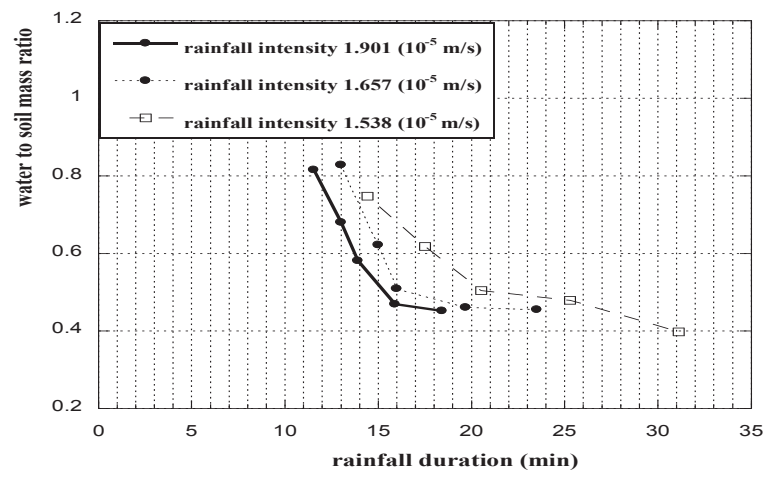

FIG.6. Relationship between rainfall intensity and the water to soil mass ratio of the cumulative total production flow. 


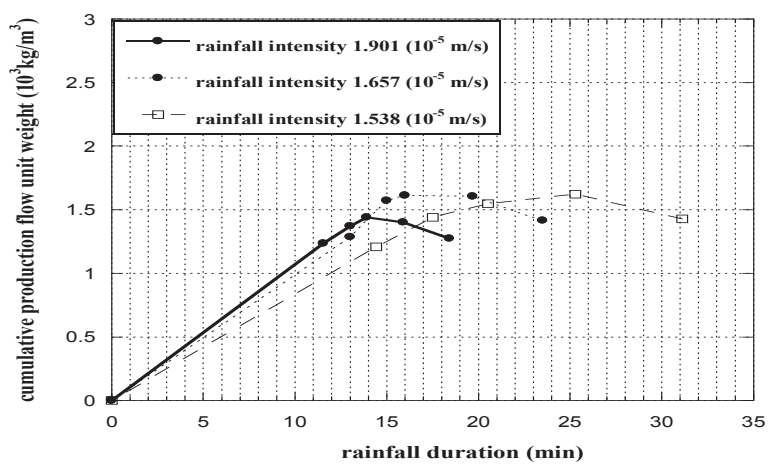

FIG.7. Relationship between rainfall intensity and the cumulative production flow unit weight.

\section{CONCLUSIONS}

Through the indoor artificial rainfall test, the process of debris flow initiation for the soil accumulated on the slope has been simulated under the rainfall action. The relationship between rainfall intensity, duration time before the starting and the total rainfall at the starting moment have been analyzed. The debris flow starting condition and confluence process have been measured in this test. All these research results can be used to present debris flow initiation mechanism originated from the seepageinduced action and its influence factors. Study on debris flow initiation through field observation and field experiment need to conduct further for the objective of the debris flow initiation mechanism.

\section{ACKNOWLEDGEMENTS}

This article's topic is based on the National Project 973 "Wenchuan earthquake mountain hazards formation mechanism and risk control" (2008CB425800), a project of the Chinese Academy of Sciences Mountain Hazards and a joint project of the Environment Institute and the Chinese Academy of Mechanics.

The authors acknowledge the project supported by the program for New Century Excellent Talents in University of Ministry of Education of China (NCET-11-1016), and supported by the program for Young Talents of Science and Technology in Universities of Inner Mongolia Autonomous Region (YTST).

\section{REFERENCES}

Anderson, S. A., and Sitar, N. (1995). "Analysis of rainfall-induced debris flows." $J$. Geotech. Eng., Vol. 121(7): 544-552.

Brand, E. W., (1981). "Some thoughts on rain-induced slope failures." Proc., 10th Int. Conf. on Soil and Mechanical Foundation Engineering, Stockholm, Sweden, Vol. 3: 
373-376.

Cui, P. (1992). "Studies on Condition and Mechanism of Debris Flow by Means of Experiment.” Chinese Science Bulletin, Vol. 37(9): 759-763.

Cui, P. (1993). "The sudden change properties of debris flow initiation." Journal of Natural Disasters, Vol. 2 (1): 53-61.

Chen, H., Lee, C. F. and Law, K. T. (2004). "Causative mechanisms of rainfallinduced fill slope failures." Journal of Geotechnical and Geoenvironmental Engineering, Vol. 130(6): 593-602.

Fleming, R. W., Ellen, S. D., and Algus, M. A. (1989). “Transformation of dilative and contractive landslide debris into debris flow-An example from Marin County," California. Eng. Geol., Amsterdam, Vol. 27: 201-223.

Iverson, R. M. and Lahusen, R. G. (1989). "Dynamic pore-pressure fluctuations in rapidly shearing granular materials.” Science. Vol. 246: 796-799.

Iverson, R. M. (1997a). “The physics of debris flows.” Reviews of Geophysics, Vol. 35(3): 245-296.

Iverson, R. M., Reid, M. E. and LaHusen, R. G. (1997b). “Debris-flow mobilization from landslides." Annual Review of Earth and Planetary, Sciences. Vol. 25: 85138.

Li, C., Zhu, W. H., Lu, X. B. and Cui, P. (2010). "Studied on landslide translating into debris flow under rainfall.” China Civil Engineering Journal, Vol. 43: 371376.

Sladen, J. A., Hollander, R. D., and Krahm, J. (1985). "The liquefaction of sand, a collapse surface approach.” Canadian Geotechnical Journal, Vol. 22(4): 564-578.

Sasitharan, S., Robertson, P. K., Sego, D. C., and Morgenstern, N. R. (1994). "Stateboundary surface for very loose sand and its practical implications." Canadian Geotechnical Journal, Vol. 31(3): 321-334.

Take, W. A. and Bolton, M. D. (2003). "Tensiometer saturation and the reliable measurement of soil suction," Géotechnique, Vol. 53(2):159-172.

Zhu, J. H., and Anderson, S. A. (1998). "Determination of shear strength of Hawaiian residual soil subjected to rainfall-induced landslides." Geotechnique, Vol. 48(1): 73-82. 